\title{
HEAT AND MASS TRANSFER IN A HIGH-POROUS LOW- TEMPERATURE THERMAL INSULATION IN REAL OPERATING CONDITIONS
}

\author{
Vyacheslav Yu. Polovnikov, ${ }^{1, a}$, Artem. M. Habibulin ${ }^{1}$, Vladimir A. Arkhipov ${ }^{2}$, Irina K. Zharova ${ }^{2}$ \\ ${ }^{1}$ National Research Tomsk Polytechnic University, 634050 Tomsk, Russia \\ ${ }^{2}$ Scientific Research Institute of Applied Mathematics and Mechanics, 634050 Tomsk, Russia
}

\begin{abstract}
The results of numerical simulation of heat and mass transfer in a high-porous low-temperature insulation in conditions of insulation freezing, a moisture migration to the front of phase transition and a condensation forming on an outer contour of interaction were obtained. Values of heat leakage were established.
\end{abstract}

\section{INTRODUCTION}

A protection of various low-temperature equipments (air conditioners, refrigerators, vessels of cryogenic liquids, etc.) from an environment exposure is an important problem [1, 2]. The one of features of a low-temperature insulation is a high probability of steam condensation on a surface or inside insulation and moisture freezing [3]. In this case, an accumulation of moisture at lowtemperature insulation leads to a considerable increase of heat leakage [4].

Mathematical models and approaches to analysis of a low-temperature equipments thermal regimes $[1,2]$ are very simple. These models and approaches disregard a nonstationarity processes of heat and mass transfer, an insulation freezing, a condensation forming on an outer contour of interaction, etc. The aim of the present paper is a mathematical modeling of heat and mass transfer in a high-porous layer of low-temperature insulation in conditions of insulation freezing, a moisture migration to the front of phase transition and a condensation forming on an outer contour of interaction.

\section{Problem statement}

We consider a cylindrical layer of high-porous low-temperature insulation to be fixed to the surface of a metal pipe. A scheme of solution domain is shown in Figure 1. For the domain under consideration (Fig. 1) we solve a 1D non-linear and non-stationary problem of heat and mass transfer in a highporous layer of low-temperature insulation in conditions of phase transitions and the dependence of insulation properties from volume concentrations of water and ice.

The external contour of insulation interacts with a humid air. Water from the humid air condenses on the external contour (Fig. 1). A moisture transfer realizes only in a moistened zone by moisture migration to the freezing front by film-diffusion mechanism of moisture transfer.

${ }^{\mathrm{a} C}$ Corresponding author: polov@tpu.ru 
The internal surface of the insulation $R_{1}$ (Fig. 1) has a constant temperature and the external surface $R_{2}$ has a convective heat and mass exchange with an environment. At the boundary of phase transitions $\xi(t)$ for problem of moisture transport was considered the condition of ideal waterproofing. The initial values of temperature $T_{0}$ and the relative moisture content of the insulation by volume $W_{0}$ in the domain of solutions (Fig. 1) have the constant values. Because of the insulation cooling is formed a variable thickness frozen layer (Fig. 1) and the movable boundary of phase transition has a constant temperature of freezing.

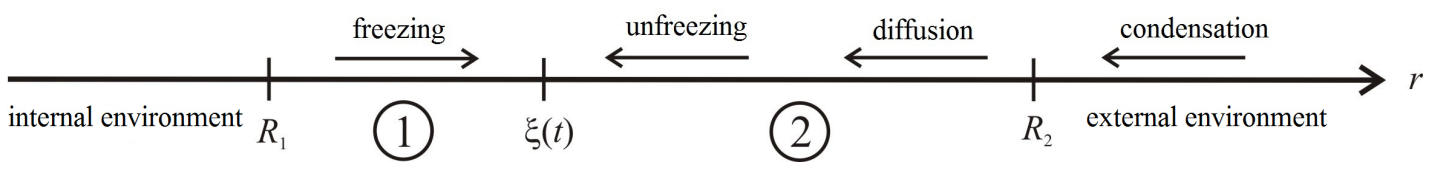

Figure 1. A scheme of decision domain: 1 - frozen zone of insulation; 2 - moistened zone of insulation.

Formulating the problem, we used the following assumptions:

1. The heat transfer processes in the internal and the external environment are disregarded.

2. The thermophysical characteristics of materials used in the analysis are constant and known values.

3. The heat in the insulation layer is transferred only by conduction.

The listed assumptions, on the one hand, do not impose constrains of principle on the physical model of the system (Fig. 1), but, on the other hand, allow one to simplify in a certain manner the algorithm and method for solving the posed problem.

\section{Mathematical model}

In the proposed statement, the heat and mass transfer process in the considered decision domain (Fig. 1) in a $1 \mathrm{D}$ formulation is described:

$$
\begin{aligned}
& \frac{\partial T_{1}}{\partial t}=a_{\mathrm{ef}, 1}\left(\frac{\partial^{2} T_{1}}{\partial r^{2}}+\frac{1}{r} \frac{\partial T_{1}}{\partial r}\right), \quad R_{1}<r<\xi(t), \quad t>0 ; \\
& \frac{\partial T_{2}}{\partial t}=a_{\mathrm{ef}, 2}\left(\frac{\partial^{2} T_{2}}{\partial r^{2}}+\frac{1}{r} \frac{\partial T_{2}}{\partial r}\right), \quad \xi(t)<r<R_{2}, \quad t>0 ; \\
& \frac{\partial W_{2}}{\partial t}=D_{2}\left(\frac{\partial^{2} W_{2}}{\partial r^{2}}+\frac{1}{r} \frac{\partial W_{2}}{\partial r}\right), \quad \xi(t)<r<R_{2}, \quad t>0 . \\
& T=T_{0}, \quad R_{1} \leq r \leq R_{2}, \quad t=0 ; \\
& W=W_{0}, \quad R \leq r \leq R_{2}, \quad t=0 . \\
& T_{1}=T_{\text {in }}, \quad r=R_{1}, \quad t>0 ; \\
& -\lambda_{\text {ef }, 2} \frac{\partial T_{2}}{\partial r}=\alpha\left(T_{2}-T_{\text {ex }}\right)-j Q, \quad r=R_{2}, \quad t>0 ;
\end{aligned}
$$




$$
\begin{aligned}
& -D_{2} \frac{\partial W_{2}}{\partial r}=\beta\left(W_{2}-W_{\text {ex }}\right), \quad r=R_{2}, \quad t>0 ; \\
& \frac{\partial W_{2}}{\partial r}=0, \quad r=\xi(t), \quad t>0 ; \\
& \lambda_{\text {ef }, 1} \frac{\partial T_{1}}{\partial r}-\lambda_{\text {ef }, 2} \frac{\partial T_{2}}{\partial r}=\bar{W} Q \bar{\rho} \frac{d \xi}{d t}, \\
& T_{1}=T_{2}, \quad r=\xi(t), \quad t>0 .
\end{aligned}
$$

The thermophysical properties of insulation were determined from the well-known expressions [5] and the effective coefficient of thermal conductivity - by the formula

$$
\lambda_{\text {ef }, 1}=W_{\mathrm{i}} \lambda_{\mathrm{i}}+\left(1-W_{\mathrm{i}}\right) \lambda_{\text {ins }}, \quad \lambda_{\text {ef, }, 2}=W_{\mathrm{w}} \lambda_{\mathrm{w}}+\left(1-W_{\mathrm{w}}\right) \lambda_{\text {ins }} .
$$

The mass transfer intensity was calculated by the formula

$$
j=\frac{\left(p_{\mathrm{st}}-p_{\mathrm{s}}\right)}{k} \text {. }
$$

\section{Method of solution and initial data}

The system of equations (refer with: Eqs. 1-12) was solved by the finite-difference method [6] using an iterational implicit difference scheme. The characteristic features of the problem solution were the discontinuity of the thermophysical characteristics and the presence of additional summands in boundary conditions (Eqs. 7 and 10).

Table 1 contains values of thermophysical characteristics, which were used in the numerical investigations of thermal conditions of the system under consideration (Fig. 1).

Table 1. Thermophysical characteristics

\begin{tabular}{|c|c|c|c|}
\hline Characteristic & $\lambda,[\mathrm{W} /(\mathrm{m} \cdot \mathrm{K})]$ & $C,[\mathrm{~J} /(\mathrm{kg} \cdot \mathrm{K})]$ & $\rho,\left[\mathrm{kg} / \mathrm{m}^{3}\right]$ \\
\hline Water & 0.6 & 4186 & 994.04 \\
\hline Ice & 2.4 & 1924 & 916.8 \\
\hline Mineral wool & 0.0426 & 702 & 100 \\
\hline
\end{tabular}

The analysis was carried out for a cylindrical object with a diameter of nominal bore of 2400 $\mathrm{mm}$; the object was manufactured from steel with thermal insulation from mineral wool $(50 \mathrm{~mm}$ thick). The ambient temperature was equal to $T_{\mathrm{ex}}=290 ; 295$ and $300 \mathrm{~K}$ and the temperature of the inner surface of the object was $T_{\text {in }}=230 \mathrm{~K}$. The values of temperature and volume humidity in the considered region at the initial instant were $T_{0}=T_{\text {in }}=230 \mathrm{~K}$ and $W_{0}=1 \%$. The relative air humidity of the environment was equal to $\varphi=60 ; 80$ and $100 \%$ and the atmospheric pressure was $p_{\text {at }}=101325 \mathrm{~Pa}$. The coefficient of heat transfer in all variants of the numerical analysis was $\alpha=5 \mathrm{~W} /\left(\mathrm{m}^{2} \cdot \mathrm{K}\right)$ and the resistance of moisture exchange was $\mathrm{k}=96(\mathrm{MPa} \cdot \mathrm{s} \cdot \mathrm{m} 2) / \mathrm{kg}$. The diffusion coefficient of moisture in the mineral wool was $\mathrm{D}_{2}=1.5 \cdot 10-3 \mathrm{~m} 2 / \mathrm{hr}$. 


\section{Results of numerical simulation}

The main results of numerical modeling of thermal and mass conditions of the system under consideration (Fig. 1) are listed in Table 2 and in Fig. 2.

Table 2 lists the results of numerical experiments of heat leakage for: in conditions of insulation freezing $\left(q_{1}\right)$ and without insulation freezing $\left(q_{2}\right)$. Also Table 1 contains the relative calculation error $\delta_{2}$, the thickness of frozen insulation $\delta$, the volume humidity of the environment $W_{\mathrm{ex}}$ and the time of the steady-state condition $t_{\text {sta }}$.

Validity and reliability of the obtained results follow from tests of the methods for convergence and stability of solutions on multiple meshes, fulfillment of the energy balance conditions at boundaries of the calculation domain, and is also confirmed by comparison of the obtained results and the known experimental [1,2] and theoretical [4] data obtained by other authors. The relative calculation error $\delta_{2}$ in all versions of the numerical analysis did not exceed $0.5 \%$, which is acceptable for investigations of thermal and mass conditions of the system under consideration (Fig. 1).Experimental studies established the boundary conditions of the ignition of coal particles with different sizes: $4 \mathrm{~mm}-850 \mathrm{~K}, 5 \mathrm{~mm}-880 \mathrm{~K}, 6 \mathrm{~mm}-930 \mathrm{~K}$. Particles ignition does not occure at the lower temperatures of the ignition source. As a result of their heating, thermal decomposition or decay of fuel particles occurs.

The numerical experimental results in Table 2 allow us to make the inference about the expected increase of heat leakage with growing a temperature of the ambient and the relative air humidity.

The data presented in Table 2 allow us to make the following conclusions:

1 . The heat leakage $q_{1}$ increases by about $35 \%$ compared with the heat leakage $q_{2}$. Therefore the role of insulation freezing in determining heat leakage becomes important.

2. The maximum value of the thickness of frozen insulation is $\delta=45.0 \mathrm{~mm}$. It corresponds to almost complete freezing of the insulation layer.

3. The thickness of frozen insulation changes by about $20 \%$ depending on the values of the temperature and the relative air humidity of the environment.

Table 2. Results of numerical simulation

\begin{tabular}{|c|c|c|c|c|c|c|c|c|}
\hline $\begin{array}{l}T_{\mathrm{ex}}, \\
{[\mathrm{K}]}\end{array}$ & $\begin{array}{c}\varphi, \\
{[\%]}\end{array}$ & $\begin{array}{c}q_{1}, \\
{[\mathrm{~W} / \mathrm{m}]}\end{array}$ & $\begin{array}{c}q_{2}, \\
{[\mathrm{~W} / \mathrm{m}]}\end{array}$ & $\begin{array}{l}W_{\mathrm{ex}}, \\
{[\%]}\end{array}$ & $\begin{array}{c}\delta \\
{[\mathrm{mm}]}\end{array}$ & $\frac{q_{1}-q_{2}}{q_{1}} \cdot 100 \%$ & $\begin{array}{c}\delta_{2}, \\
{[\%]}\end{array}$ & $\begin{array}{l}t_{\text {sta }}, \\
{[\mathrm{hr}]}\end{array}$ \\
\hline \multirow{3}{*}{290} & 60 & 500.7 & \multirow{3}{*}{343.3} & 1.14 & 45.0 & 31.4 & 0.49 & 1.5 \\
\hline & 80 & 512.6 & & 1.53 & 44.1 & 33.0 & 0.34 & 2.1 \\
\hline & 100 & 524.9 & & 1.91 & 43.1 & 34.6 & 0.30 & 2.3 \\
\hline \multirow{3}{*}{295} & 60 & 538.7 & \multirow{3}{*}{371.9} & 1.56 & 41.8 & 31.0 & 0.50 & 1.8 \\
\hline & 80 & 557.5 & & 2.09 & 40.6 & 33.3 & 0.30 & 2.5 \\
\hline & 100 & 572.7 & & 2.61 & 39.3 & 35.1 & 0.45 & 2.7 \\
\hline \multirow{3}{*}{300} & 60 & 582.0 & \multirow{3}{*}{400.5} & 2.11 & 38.7 & 31.2 & 0.35 & 2.1 \\
\hline & 80 & 606.1 & & 2.82 & 37.1 & 33.9 & 0.46 & 2.7 \\
\hline & 100 & 500.7 & & 3.54 & 35.6 & 36.7 & 0.36 & 3.5 \\
\hline
\end{tabular}




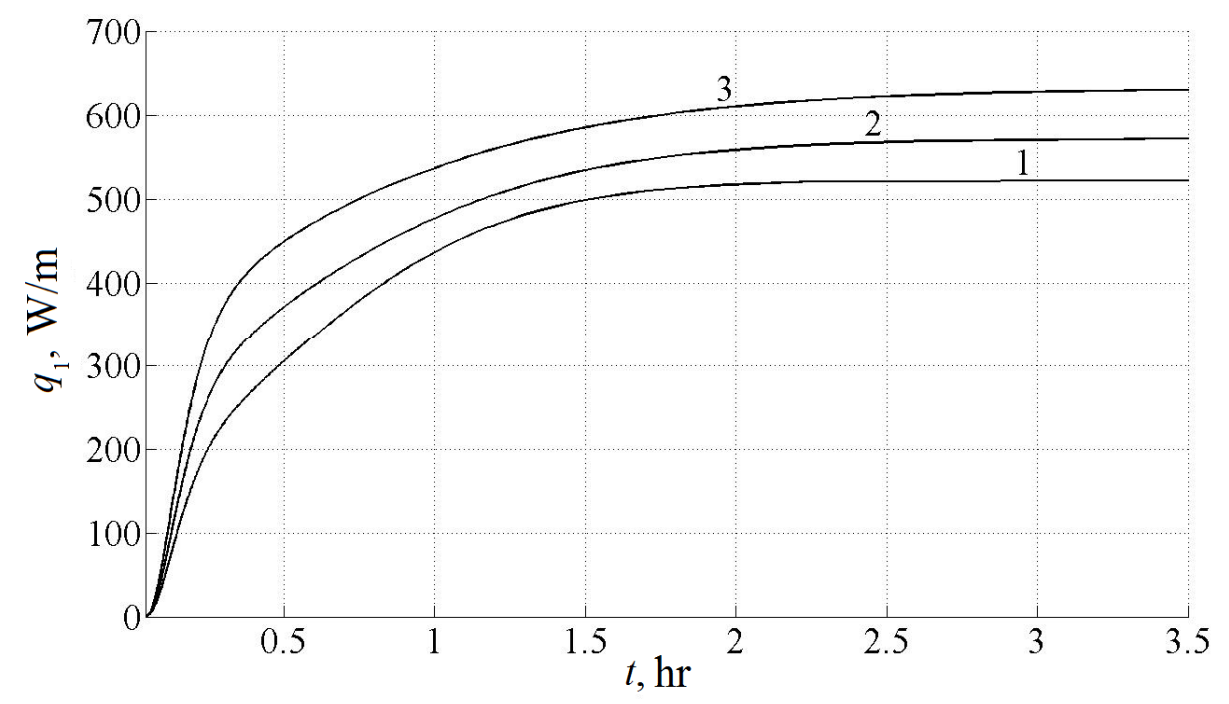

Figure 2. Temporal variation of the heat leakage $(\varphi=100 \%): 1-290 \mathrm{~K} ; 2-295 \mathrm{~K} ; 3-300 \mathrm{~K}$.

Figure 2 shows the nonstationary of heat and mass transfer of the system under consideration (Fig. 1). An analysis of nonstationary processes of heat and mass transfer of the system under consideration allow us to make the inference about what time to steady-state condition is from 1.5 to 3.5 hours (Table 2). From analysis of results shown in Fig. 2, it is seen that the process of heat and mass transfer turns out to be not nonstationary.

\section{Conclusion}

We have carried out numerical analysis of thermal and humidity regimes and numerical analysis of heat leakage in a a high-porous low-temperature insulation in conditions of insulation freezing, a moisture migration to the front of phase transition and a condensation forming on an outer contour of interaction.

It has been shown that the heat leakage increases by about $35 \%$ and time to steady-state condition is from 1.5 to 3.5 hours.

In summary, the application of the proposed approach enables comprehensive analysis of thermal and humidity regimes of the system under consideration.

\section{Notations}

$R$ - domain boundary; $\xi$ - boundary of phase transitions; $T$ - temperature, $\mathrm{K} ; W$ - relative moisture content; $a$ - thermal diffusivity, $\mathrm{m}^{2} / \mathrm{sec} ; t$ - time, sec; $r$ - coordinate, $\mathrm{m} ; D$ - diffusion coefficient, $\mathrm{m}^{2} / \mathrm{sec} ; \lambda$ - thermal conductivity, $\mathrm{W} /(\mathrm{m} \cdot \mathrm{K}) ; C$ - heat capacity, $\mathrm{J} /(\mathrm{kg} \cdot \mathrm{K}) ; \rho$ - density, $\mathrm{kg} / \mathrm{m}^{3} ; \alpha-$ heat transfer coefficient, $\mathrm{W} /\left(\mathrm{m}^{2} \cdot \mathrm{K}\right) ; j-$ mass transfer intensity, $\mathrm{kg} /\left(\mathrm{m}^{2} \cdot \mathrm{sec}\right) ; Q$ - heat of phase transition, $\mathrm{J} / \mathrm{kg} ; \beta$ - mass-transfer coefficient, $\mathrm{m} / \mathrm{sec} ; \varphi$ - relative air humidity, $\% ; k$ - resistance of moisture exchange, $\left(\mathrm{MPa} \cdot \mathrm{s} \cdot \mathrm{m}^{2}\right) / \mathrm{kg} ; p$ - pressure, $\mathrm{Pa} ; t_{\mathrm{sta}}$ - time of the steady-state condition, $\mathrm{hr} ; \delta_{2}$ - relative calculation error, \%; $\delta$ - thickness of frozen insulation, $\mathrm{mm} ; q$ - heat leakage , W/m; $\bar{\rho}=\left(\rho_{\mathrm{w}}+\rho_{\mathrm{i}}\right) / 2-$ mean density, $\mathrm{kg} / \mathrm{m}^{3} ; \bar{W}=\left(W_{\mathrm{w}}+W_{\mathrm{i}}\right) / 2$ - mean relative moisture content. Indices: 1 and 2 - numbers of calculation domains (Fig. 1); 0 - initial time; ex - external environment; in - internal environment; ef - effective; i - ice; s - saturation, w - water; atm - atmospheric, st steam; ins - insulation.. 


\section{References}

1. K.D. Timmerhaus, R.P. Reed, Cryogenic Engineering, Springer, New York, 2007.

2. K.D. Timmerhaus, T.M. Flynn, Cryogenic Process Engineering, Springer, New York, 1989.

3. T.H.K. Barron, G.K. White, Heat Capacity and Thermal Expansion at Low Temperatures, Springer, New York, 1999.

4. V.Yu .Polovnikov, .V. Piskunov, Numerical probability analysis of lowtemperature insulation destruction under the condition of periodic duty, EPJ Web of Conferences. 76 (2014) 01030/

5. G. Ventura, M. Perfetti, Thermal Properties of Solids at Room and Cryogenic Temperatures, Springer Netherlands, 2014.

6. A.L. Garcia, Numerical methods for physics, Prentice Hall, New York, 2000. 